\title{
Factors Affecting Infertility and Role of Growth Hormone in Management of Female Infertility: A Review
}

\author{
Firas Salih Abdulhadi', Dalal A. Sattar ${ }^{1}$, Sabah Abd AL-Hameid Abd AL-Rahman ${ }^{2}$, Jomana Sabah ${ }^{3}$ \\ ${ }^{1}$ Assistant lecturer, Department of biology, College of science, Mustansiriyah University, Baghdad, Iraq, ${ }^{2}$ Professor, \\ Department of biology, College of science, Mustansiriyah University, Baghdad, Iraq, ${ }^{3}$ Lecturer, MBChB, Medicine \\ City-Ministry of Health, Baghdad, Iraq
}

\begin{abstract}
At our review we will discuss the definition of infertility according to the World Health Organization (WHO), types of infertility, factors determine fertility, factors affecting infertility in both men\&female as Body mass index (BMI), hormones and life style changes that are increasing in the current years and factors as (stress and smoking). Also discuss the role of Growth Hormone (GH) in management of women infertility.
\end{abstract}

Keywords: Infertility; Body mass index; Growth Hormone.

\section{Introduction}

Infertility is a major health problem that couple faces during their life. Reproduction helps the community to produce new generation for continuity of human beings in life also some communities have social concerns about reproduction as they considerate as a fortune and the couples may undergo social pressure from their families and society to have their own offspring's. Sterility is anillness concerns the propagative device determine viafiasco toward accomplish gestation afterward 12 months or additional (1). Men infertility may be due to impaired sperm count, motility and morphology ${ }^{(2)}$. Infertility may be primary or secondary infertility. Primary infertility, when pregnancy is not achieved more than $1 \mathrm{yr}$. Secondary infertility where 1 or more pregnancies in the past, but are having difficulty conceiving again ${ }^{(3)}$.

Factors Determining Fertility: Factors that determine man fertility ejaculation of motile sperm (40-250 million per $\mathrm{ml}$ ). Every sperm takes ten weeks to be created by spermatogenesis, when sperm count fall beneath 14-40 million for each $\mathrm{ml}$ will impairs fertility (Fig.1) ${ }^{(4)}$, at every low sperm counts (under 5 million for each $\mathrm{ml}$ ) in these men,may have abnormal morphology ${ }^{(5)}$, the number of sperm of sperm created every day is controlled by number of Sertoli cells $(6,7)$. Sertoli cells number is the main factor that affects sperm counts ${ }^{(7,8)}$ (Fig1). The male reproductive organs inside (testes, prostate gland, vas deferens and epididymis) and externally (scrotum). The descent of testis in scrotum occurs by birth, in complete descent of testis (cryptorchidism) because low sperm count and increase risk of testicular cancer ${ }^{(6,9}$ and 10$)$.

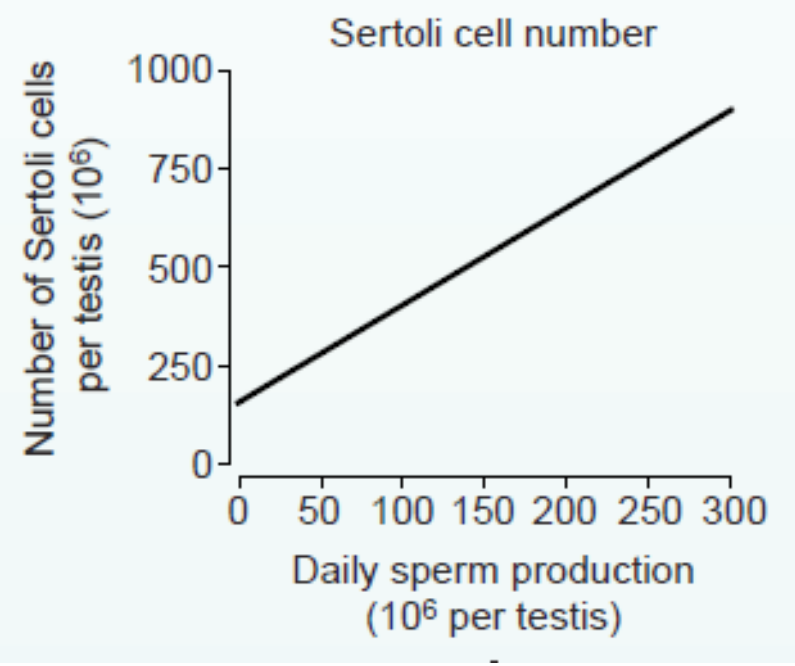




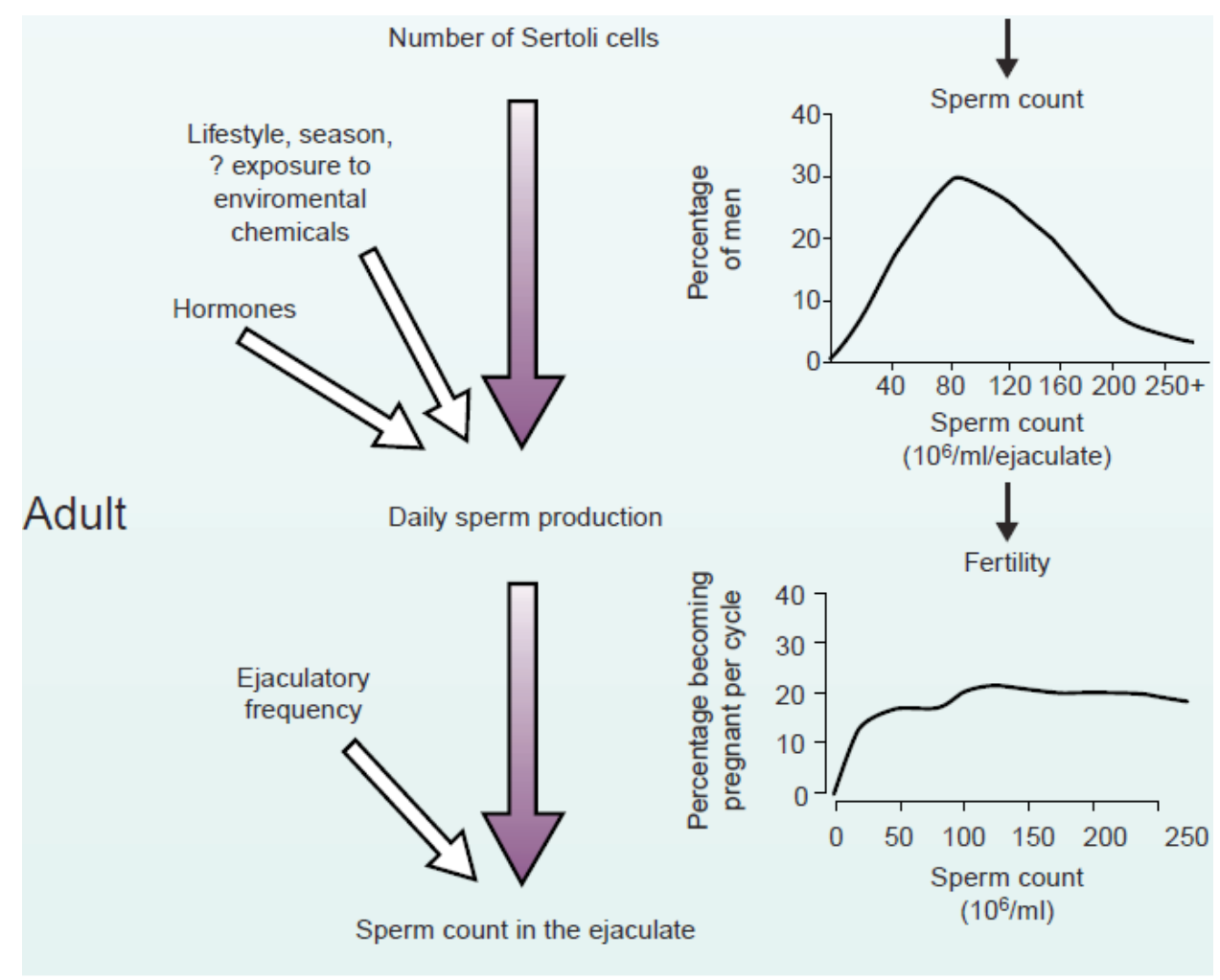

Fig (1): Sperm counts affect male fertility depend mainly on amount of Sertoli cells in the testes, propagation from Sertoli cells is influenced through regulatory substance,environmental factors as sperm count below 40 million per ml decreases fertility.

In woman, fertility depend on monthly ovulation of oocyte Fig (2) within female reproductive organs (Ovary, fallopian tubes \& uterus),production of mature oocyte able to be fertilized by menstrual cycle ${ }^{(11,12)}$, five hundred oocytes might be ovulated in puberty. The elementary oocyte in fetal ovary captured in first meiotic prophase and staydominant till maturation resume activity in puberty triggered by follicle stimulating hormone (FSH) that stimulate follicle maturation producing estrogen to start growth of endometrium of uterus then section luteinizing hormone (LH) in mid cycle stimulate ovulation Fig (2).

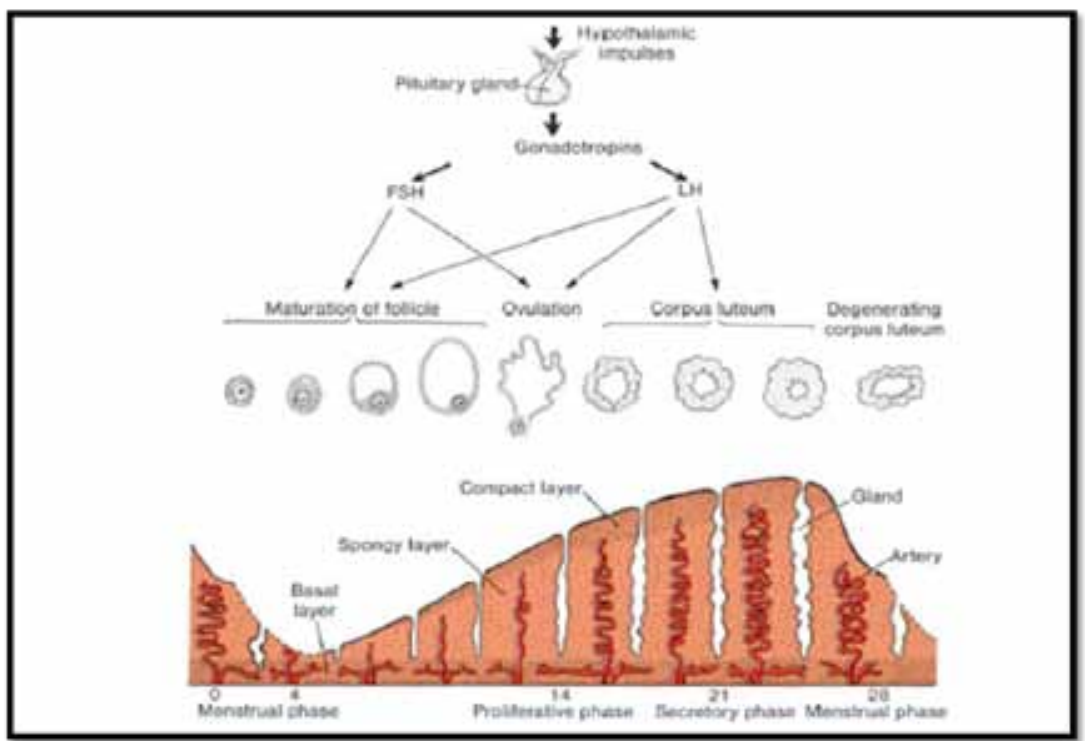

Fig (2): Female hormonal regulation with changes endometrium and corresponding changes in the ovary during regular menstrual cycle without fertilization. 


\section{Factors affecting infertility}

Body mass index (BMI): Body-mass-index (BMI) has minimum impaction on malesemenenumeration, however ability own majorpossessionsat feminine fecundity ${ }^{(13)}$. within a womanly of regular weighing $\&$ nutrition (Fig.3a), control of follicle maturation and ovulation by LH and FSH liberate from the pituitary gland. The emission of LH and FSH is directed by gonadotropin emission hormone. FSH in addition LH adjust maturation about cavities within the ovary, whose stimulate production of (testosterone, estradiol and progesterone) these hormones act on the uterus. Women with anorexia nervosa (Fig.3b) scarcely have normal and regular menstrual cycle ${ }^{(14)}$. The action of ovaries starts to diminish due tofall in $\mathrm{GnRH}$ production,causing gonadotrophin concentrations very few to sustain ovarian function. Leptinconcentricity are least within below a weight lady such might be the agent such diminishes emission about GnRH (Fig.3b). Obesity on the other hand leads to sexual problems (Fig.3c) $)^{(15)}$.

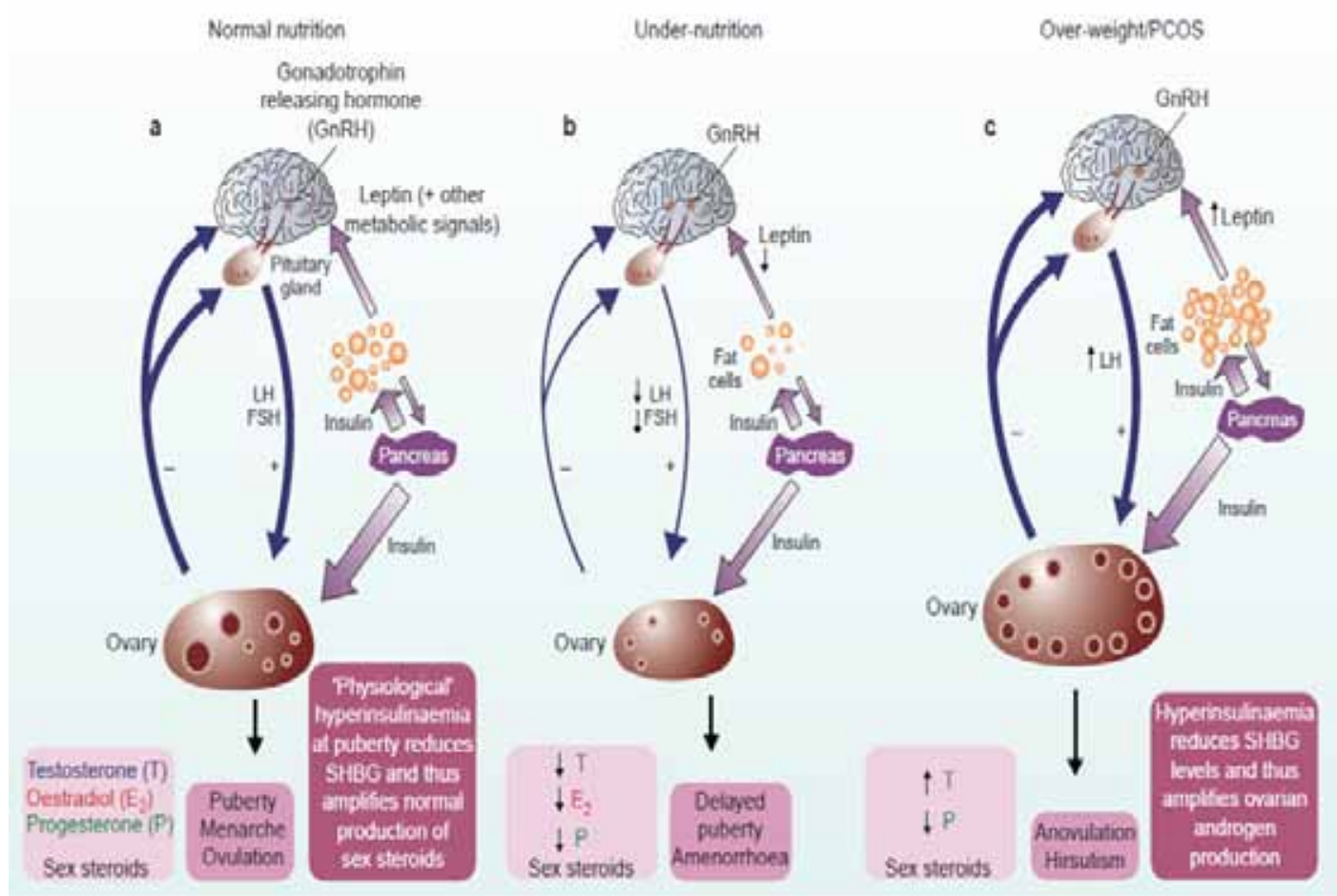

Fig (3): Regulation the secretion of GnRH causes secretion of LH\& FSH from pituitary gland. Nutrition play role in female fertility by effect of Leptin hormone from fat cell\& insulin from pancreas that alter presence of estradiol \& testosterone $(T)$.

Deficiency about these gender sex hormone results in an nonappearance about follicular development,on the other hand, in overweight ladies or potentially with polycystic ovary syndrome (PCOS), raise leptin and insulin scale and an expansion within LH, rather than FSHscale result infraction al expansion of cavitiessuch excrete supernormal scale from testosterone, nevertheless scarcely ovulate (consequentlyleast progesterone ovaries testosterone manufacture/activity to PCOS[4]. The link between overweight and polycystic ovary syndrome as ovary contains immature follicles is one of the prevalentreasons for infertility cause an ovulation (16). Its etiology is mysterious, but genetic factors are important, polycystic ovaries are linked with hormone abnormalities (overabundance emission of testosterone by the ovary).Be that as it may, there is additionally an interaction with nutrition. Polycystic ovariesare described by metabolic disturbances, including anintestinalobesity, in addition to resistance to and over-excretion of insulin ${ }^{(17)}$. The outcomes ofabdominal obesity in ladieswith polycystic ovaries incorporate an expanded possibility of anovulation and infertility, 
increased testosterone (bringing about undesirable male pattern hair) and, danger of creating type- 2 diabetes in later life ${ }^{[17]}$.

Hormones: GnRH is released from neurons in hypothalamus andstimulates the secretion of $\mathrm{LH}$ and FSH from the anterior pituitary gland, LH activates the interstitial cells of testes for testosterone release. FSH activates sustentacular cells of the seminiferous tubules to increase spermatogenesis and to secrete inhibin. In research done in Iraq by ${ }^{(18)}$, about the effect of hormones on infertility among men \& women.

Table 1 shows no significant difference between BMI in healthy men $(26.11 \pm 2.31)$ or infertile ones $(25.45 \pm 1.34) \mathrm{kg} / \mathrm{m}^{2}$. But there were absolute variations between serum LH and serum FSH. The mean serum LH level of these infertile men $(7.895 \pm 0.85) \mathrm{mLU} / \mathrm{ml}$ in comparison with $(2.12 \pm 0.31) \mathrm{mLU} / \mathrm{ml}$ of the normal men. This outcome is high of thenormal $\mathrm{LH}$ value and also it significant. The serum FSH was $(9.89 \pm 1.12)$ $\mathrm{mLU} / \mathrm{ml}$ in the infertile men in contrast with the values in the control group which were lower $(3.39 \pm 1.45)$ $\mathrm{mLU} / \mathrm{ml}$. This result is supported by[19] which showed that the plasma FSH scalewas $26.40 \pm 11.43 \mathrm{mLU} / \mathrm{ml}$ within the check collection in contrast with the scale within the monitoring group was $3.71 \pm 1.25 \mathrm{mLU} / \mathrm{ml}$, yonder was a remarkable link $(r=0.67)$ amongplasma FSH besides the semenamount. Serum prolactin increases in the infertile men and reach to $(13.33 \pm 2.15)$ $\mathrm{ng} / \mathrm{ml}$ compared to the monitoring assembly $(5.65 \pm 3.34)$ $\mathrm{ng} / \mathrm{ml}$. This result agrees with ${ }^{(19)}$ who showed that the mean serum prolactin in test group was $(18.01 \pm 1.28) \mathrm{ng} /$ $\mathrm{ml}$, compared to $(5.43 \pm 2.02) \mathrm{ng} / \mathrm{ml}$ of the monitoring assembly, these results is extra than double the control prolactin worth and is highly considerable $(p<0.01)$. Also, (20) showed that the prolactin may suppress the production of GnRH and leading to testicular dysfunction in associated with spermatogenic arrest and decreased serum testosterone concentration. On the other hand, ${ }^{(21)}$ showed that any insult in the hypothalamus or pituitary (hypogonadotropic-hypogonadism) whose results in lower serum FSH \& LH through increase within plasma prolactin scale may possibly causes sterility. Hyper-prolactinemia occur when excess secretion from lactotrophs in anterior pituitary ${ }^{(20)}$. Prolactin induce apoptosis in spermatogonal stage of the testes but FSH to these tissue societies switches these progressions, increases secretion for a long time of FSH can induce sperm production, inazoospermia is reversible ${ }^{(22)}$.

Table (1): Compare of BMI, plasma LH, FSH, prolactin, testosterone and Leptin in the infertile and normal men [18].

\begin{tabular}{|l|c|c|c|}
\hline Parameters & $\begin{array}{c}\text { Infertile men } \\
\mathbf{n = 2 1}\end{array}$ & $\begin{array}{c}\text { fertile men } \\
\mathbf{n = 1 2}\end{array}$ & Normal average \\
\hline BMI $\left(\mathbf{k g} / \mathbf{m}^{\mathbf{2}}\right)$ & $25.45 \pm 1.34$ & $26.11 \pm 2.31$ & \\
\hline $\mathbf{L H}(\mathbf{m L U} / \mathbf{m l})$ & $7.895 \pm 0.85$ & $2.12 \pm 0.31^{* *}$ & $1.1-7$ \\
\hline FSH $(\mathbf{m L U} / \mathbf{m l})$ & $9.89 \pm 1.12$ & $3.39 \pm 1.45^{* *}$ & $1.7-12$ \\
\hline Prolactin $(\mathbf{n g} / \mathbf{m l})$ & $13.33 \pm 2.15$ & $5.65 \pm 3.34 * *$ & $1.5-19$ \\
\hline Testosterone $(\mathbf{n g} / \mathbf{d l})$ & $3.91 \pm 0.51$ & $21.76 \pm 1.45^{* *}$ & $3-10$ \\
\hline Leptin $(\boldsymbol{\mu g} / \mathbf{L})$ & $9.40 \pm 0.44$ & $2.95 \pm 0.35^{* *}$ & $3.84 \pm 1.79$ \\
\hline
\end{tabular}

Data expressed as mean $\pm \mathrm{SD} * * \mathrm{P}<0.01$ : Highly significant difference.

The level of testosterone hormone $(\mathrm{ng} / \mathrm{ml})$ has low significant difference $(3.91 \pm 0.51) \mathrm{ng} / \mathrm{dl}$ in test group in comparison with control group $(21.76 \pm 1.45) \mathrm{ng} / \mathrm{dl}^{(23)}$. This result agrees with ${ }^{(19)}$ who found that testosterone levels markedly less $(4.10 \pm 2.23) \mathrm{ng} / \mathrm{dl}$ within exam assemblage in comparison with the monitoring collection $(14.02 \pm 2.48) \mathrm{ng} / \mathrm{dl}$. Low levels of testosterone hormone may be resulted from the conversion of testosterone to estradiol by the aromatase enzyme effectfrom adipose tissue. Obese males who are rich with aromatase activity have more androgens converted into estrogen causing rise in estrogen level and a drop of androgen in the serum $^{(23)}$. Serum leptin has highly significant $(p<0.01)$ increase in the infertile $(9.40 \pm 0.44) \mu \mathrm{g} / \mathrm{L}$ compared with normal men values $(2.95 \pm 0.35) \mu \mathrm{g} / \mathrm{L}$. Leptin is an important adipose tissue derived hormone, takes a 
role in regulating body weight, immune function and reproduction ${ }^{(24)}$, As a result, leptin levels increases with obesity ${ }^{[23]}$. Male obesity not only impact negatively on male reproductive potencybylessens sperm quality,but also adjusting the physicaland cellular structure of germ cell and eventually full-grown sperm ${ }^{(25)}$.

Development hormone in the arrangement of womanly sterility: Growth hormone is secreted not only from the pituitary as well as locally by the ovaries. It attaches to growth hormone receptors on surface of granulosa, the thecal and luteal cells, inducing steroidogenesis and gametogenesis ${ }^{(26)}$. Growth hormone play role in ovulation process in variable steps and cangrowing ovarian sensitivity to receive gonadotropin and promotesfollicular formation ${ }^{(27)}$.

When GH receptor-deficient the development of the follicle is delayed, growth hormonebesides IGFItogetheract a function within the secretion from the follicle from hisassociation, and this causes eventually monofollicular development in female ${ }^{(26)}$. In case of lower growth hormone, this leads to decreased plasma scale of IGF-I inhibit the follicle afterrising IGFIscale. Such averts of somewhat variance within the susceptibility to FSH of the various association follicle, and permitssimilar multifollicular evolution. Through GHremediation, a variantsusceptibility to FSH amongst that folliclein additionher association are gained backvia advanced IGF-Iscale, promptingmonofollicular development. In place of the follicle develops,atomic and cytoplasmic happen take place inside the oocyte to permitoocyte fertilization.

Dosage of GH co thereby: Doses utilized have run from 0.9 to 1.8 Milligrams per week, and growth hormoneis ceased once conception is accomplished ${ }^{(28)}$. Past investigations have utilized a lot higher doses. GH has been given every day or on interchange datesin doses running from (12 to 24 international unit $)^{(26)}$. One researcher has recommended an everyday weight-based dose (0.1 international unitper kilogram $)^{(29)}$ whereas else has compared 4 international unit every day and 12international unit day by day ${ }^{(30)}$. GH co-therapy has an unmistakable task to carry out isovarian incitement, and is viable in suitably selected cases;more studies should be done to recognize effective and efficient GH treatment regimenstoo improve quiet determination. Attempts should also be made to examine the impact of growth hormone treatment on oocyte fertilization and endometrial susceptibility.
Infertility is a multifactorial health problem may be affected by nutrition's: Nutrition plays an important role infertility and undernutrition may be associated with stress or obesity that may affect female by causing (PCOs) and in male affecting semen parameters ${ }^{(31)}$, we recommend having health balanced diet with doing activates. Hormones as FSH, LH, prolactin\& testosterone may cause hormone disturbance for both male and female.Life style changes as smoking and alcohol will have negative impact on aspects of fertility in both sexes.

\section{Some causes of infertility in both sexes preventable by many ways as}

- Stop smoking.

- Limitation of alcohol consumption.

- Practice daily activities.

- Avoid thing lead to prolonged heat for testicles.

- Avoid exposure to pesticides, heavy metals and other toxins.

\section{Conclusion}

Reproduction helps the community to produce a new generation for continuity of human beings in life also some communities exert social pressure on inertial couples although it's a saved simply by seeking medical care to exclude the multifactorial causes and care the causing problems.

Acknowledgments: We acknowledge the support and scientific advice of the entire staff of Biology Department and Mustansiriyah University BaghdadIraq.

Ethical Clearance: The Research Ethical Committee at scientific research by ethical approval of both environmental and health and higher education and scientific research ministries in Iraq.

Conflict of Interest: The authors declare that they have no conflict of interest.

Funding: Self-funding

\section{References}

1. Zegers-Hochschild F, Adamson GD, De Mouzon $\mathrm{J}$, Ishihara $\mathrm{O}$, Mansour $\mathrm{R}$, et al. International Committee for Monitoring Assisted Reproductive Technology (ICMART) and the World Health 
Organization (WHO) revised glossary of ART terminology. Fertil Steril. 2009; 92: 1520-1522. WHO. Laboratory manual for the examination of human semen and sperm-cervical mucus interaction (4th edn), Geneva, World Health Organization, Switzerland. 1999.

3. Sharma A. Male Infertility; Evidences, Risk Factors, Causes, Diagnosis and Management in Human. Ann Clin Lab Res. 2017;5: 3:188.

4. Richard M. Sharpe and Stephen Franks. Review. Nature Cell Biology\& Nature Medicine.

5. Irvine, D. S. Epidemiology and an etiology of male infertility Human. Reproduction. 1998; 1, 33-44.

6. Sharpe, R.M. Environment, lifestyle and male infertility. Baillieres Clin. Endocr.Metab.2000; 14, 489-503.

7. Sharpe, R.M. Fetal/neonatal hormones and reproductive function of the male in adulthood in fetal programming: influences on development and disease in later life. (Eds O'Brien, P. M. S., Wheeler,T.\& Barker,D. J. P)1999; 187-194 .

8. Johnson, L.,Zane, R. S.,Petty, C. S.\& Neaves,W. Quantification of the human Sertoli cell population: its distribution, relation to germ cell numbers and age-related decline. Biol. Reprod. 1984; 31, 785795 .

9. Toppari, J. et al. Male reproductive health and environmental xenoestrogens. Environ. Health Perspect. 1996; 104; 4, 741-803.

10. Boisen, K. A.,Main,K. M., Rajpert-de Meyts, E. \& Skakkebaek, N. E. Are male reproductive disorders a common entity? The testicular dysgenesis syndrome.Ann. NY Acad. Sci.2001; 948, 90-99.

11. Gosden, R. Ovulation 1: oocyte development through life in Gametes - The oocyte (eds Grudzinskas, J. \& Yovich, J.).1995; 119-149 (Cambridge Univ. Press,Cambridge.

12. Hardy, K.,Wright, C. S., Franks, S.\& Winston,R.M. In vitro maturation of oocytes. Br.Med. Bull.2000; 56, 588-602.

13. Sebire,N. J. et al. Maternal.Obesity and pregnancy outcome: a study of 287,213 pregnancies in London. Int. J.Obes. Relat.Disord.2001; 25, 11751182.

14. Franks, S.,Robinson, S. \& Willis,D.Nutrition. Insulin and polycystic ovary syndrome (review). Rev. Reprod.1996; 1, 47-53.
15. Grinspoon, S.,Gulick,T. \& Askari,H. Serum leptin levels in women with anorexia nervosa. J. Clin. Endocrinol. Metab.1996; 81, 3861-3863.

16. Franks, S. Medical Progress Article: Polycystic ovary syndrome (review). N.Engl. J.Med.1995; 333, 853-861.

17. Dunaif, A. Insulin resistance and the polycystic ovary syndrome: mechanism and implications for pathogenesis. Endocr. Rev.1997; 18, 774-800.

18. Sabah A.Hameid A.Rahman and Firas Salih Abdulhadi the correlation between the sociodemographic characteristics and some hormones with the infertility of women and men. Journal for Pharmaceutical Sciences.2018; 18:1.

19. Shahroona, M.; Fatima, M. and Muhammad, U.B. Severe hyperprolactinemia directly depresses the gonadal activity causing infertility.2007;2; 4 .

20. Monireh Ghorbani and Gholamhassan Vaezi. Hyperprolactinemia: effect on reproduction, cancer, behavior and obesity. Inter. J. Rec. Sci. Res.2006; 7; 4, pp. 10530-10532.

21. Emokpae, M.A. "Hormonal Evolutions and Endometrial Biopsy in Infertile Women in Kano, Northern Nigeria. Annals of African, Medicine.2005; 4: 99 -103.

22. Yazawa, T.; Yamananoto, T. and Abc, s. Prolactin induces apoptosis in the penultimate spermatogonial stage of the testes in Japanese red bellied newr. Endo. 2000; 141(6): 2027-32.

23. Chou, K. and Perry, C.M. Metreleptin. First global approval Drugs.2013; 73(9); 989-997.

24. Friedman, J. 20 years of leptin: leptin at 20: an overview. J. Endocrinal.2014; 233, 1-8.

25. Silva, D.B.S.; Crispim, B.A.; Silva, L.E.; Oliveira, J.A.; Siqueira, F; Seno L.O. et al.,. Genetic variation in the leptin gene associated with growth and carcass traits in Nellore cattle. Geneti. Molecu. Res.2014;13: 3002-3012.

26. S Kalra, B Kalra, A Sharma, M Thakral, A Ahalawat. Growth hormone in the management of female infertility. The Internet Journal of Endocrinology.2008;5: 2.

27. Mariusz T. Skowronski, Patrycja Mlotkowska, Damian Tanski, Ewa Lepiarczyk, Michal K. Oklinski, Soren Nielsen and Agnieszka Skowronska. Pituitary Gonadotropins, Prolactin and Growth Hormone Differentially Regulate 
AQP1 Expression in the Porcine Ovarian Follicular Cells. Inter.Jour. Molec. Sci.2018; 19(1): 5.

28. Giampietro A, Milardi D, Bianchi A, et al. The effect of treatment with growth hormone on ertility outcome in engonadal women with growth hormone deficiency: report of four cases and renew of the titerature. Fertil Steril .2009; 91(3): 930.e7e11.

29. Bergh C, Hillensjo T, Wikland M, Nilsson L, Borg G, Hamberger L. Addjuvant growth hormone treatment during in vitro fertilization: a randomized, placebo-controlled study. Fertil Steril.1994; 62:113-20.

30. Suikkari AM, MacLachlan V, Koitinen R, Seppala M, Healy DL. Double-blind placebo-controlled study: human biosynthetic growth hormone for assisted reproductive technology. Fertility \& sterility.1996; 65(4):800-5.

31. Neelima Panth, Adam Gavarkovs, Martha Tamez and Josiemer Mattei. The Influence of Diet on Fertility and the Implications for Public Health Nutrition in the United States. 2018. Front Public Health. 